\title{
Coexistence of multi-deformation modes in beta Ti alloys with improved yielding strength and ductility
}

\author{
Guanfang Chen ${ }^{\mathrm{a}}$, Jinyong Zhang ${ }^{\mathrm{a}}$, Yangyang Fu${ }^{\mathrm{a}}$, Zheng Chen ${ }^{\mathrm{a}}$, Fan Sun ${ }^{\mathrm{b}^{*}}, \mathrm{Ju} \mathrm{Li}^{\mathrm{c}}$ \\ a. School of Material Science and Engineering, China University of Mining and Technology, Xuzhou, Jiangsu 221008, China \\ b. PSL Research University, Chimie ParisTech-CNRS, Institut de Recherche de Chimie Paris, 75005 Paris, France
}

c. Department of Nuclear Science and Engineering and Department of Materials Science and Engineering, Massachusetts Institute of Technology, 77 Massachusetts Avenue, Cambridge, MA 02139, USA

Corresponding author: J.Y. Zhang and F. SUN

jyzhang@,cumt.edu.cn and sun.fan@chimieparistech.psl.eu

\begin{abstract}
:
By suppressing SIM (stress induced martensitic) phase transformations, a strong and ductile beta TWIP (twinning induced plasticity) Ti-Mo based alloy was achieved, thanking to the coexistence of mechanical twinning $(\{112\}<111>$ mode and $\{332\}$ $<113>$ mode) and dislocation glide. The alloy displayed extra high yielding stress, stable strain-hardening rate and adequate ductility. In-situ traction/EBSD technique and TEM characterizations were employed to investigate the plastic deformation mechanism. The dislocation slipping was mediated by bimodal twinning mechanism, composed by high density nano-scale $\{112\}$ twinning in micro $\{332\}$ twinning grid. The study aims to exploit novel design strategy for strengthening ductile TWIP Ti alloys, attributed to multimodal twinning effects.
\end{abstract}

Keywords: beta Ti-alloys; deformation mechanisms; bimodal twinning; dislocation slip

\section{Introduction}

As an important category of Ti alloys, beta Ti-alloys have been attractive materials for aerospace, biomedical and sporting goods industries and automotive applications due to their their high strength-to-density ratio [1, 2], good hardenability [3, 4], excellent fatigue/crack-propagation behavior [5] and good corrosion resistance $[\mathbf{1 , 6}$. In the $\beta$ Ti-alloys, activation of different deformation mechanisms is strongly dependent on the metastability of the $\beta$ phase. It has been shown that with increasing the $\beta$ phase stability, the main deformation mechanism shifts from stress-induced martensite (SIM) transformation to mechanical twinning $(\{332\}<113>$ type and $\{112\}<111>$ ) $[7,8]$. The reversible SIM transformation leads to pseudo-elasticity and limited yielding stress (related to CRSS) [9-11]. On the other hand, the $\{332\}<113>$ twinning network happened in alloys with increased beta stability results in significant work hardening $[12,13]$ by dynamic HP effect via reducing the mean free path of dislocation slip in BCC crystals usually without work-hardenability [14]. Therefore, controlling the $\beta$ phase stability and thereby tailoring the deformation mechanisms has a key role in optimizing the mechanical properties of $\beta$ Ti-alloys. Recently, considerable effort has been devoted to developing a new family of $\beta$ titanium alloys with TWIP/TRIP effects (twinning-induced plasticity (TWIP) and transformation-induced plasticity (TRIP)). For instance, $\beta$ titanium alloys with a combination of TRIP and TWIP deformation mechanism generally exhibit a low yield strength, a high strain hardening rate and large uniform elongation [15-22]. As reported in various TRIP/TWIP Ti alloys, the stress plateau after elastic limit was usually related to SIM, resulting low YS, softening effect but enhancing the uniform ductility. In contrast, $\beta$ titanium alloys with twinning and dislocation slip deformation mechanism result in a relatively higher yield strength, and a stable hardening rate [13, 14, 23]. The main twinning mode most observed in the TRIP/TWIP or single TWIP alloy is $\{332\}$ type, whereas $\{112\}$ type twinning is merely employed as major deformation mechanism. Therefore, a new design idea of TWIP Ti alloy is proposed in this research by using the coexistence of $\{112\}$ and $\{332\}$ type twinning. The aim is to further strengthen this type of alloy with a better balance between stable hardening rate and ductility.

(C) The Authors, published by EDP Sciences. This is an open access article distributed under the terms of the Creative Commons Attribution License 4.0 (http://creativecommons.org/licenses/by/4.0/). 
In this work, a ternary alloy, Ti-18Zr-13Mo (wt. \%), was designed to suppress SIM (stress induced martensitic) phase transformations while keep the coexistence of multiple deformation twinning. In-situ traction/EBSD technique and TEM characterizations were employed to investigate the plastic deformation mechanism. The study aims to exploit novel design strategy for strengthening ductile TWIP Ti alloys, attributed to multimodal twinning effects.

\section{Experimental procedures}

The ternary Ti-18Zr-13Mo (wt. \%) alloy ingot was fabricated by the arc-melting furnace under pure Ar atmosphere using pure titanium, molybdenum and zirconium. Then, the ingot was homogenized at $1173 \mathrm{~K}$ for $72 \mathrm{ks}$ under high vacuum, followed by water quenching. The as-quenched ingot was heavily cold rolled to $0.5 \mathrm{~mm}$ in thickness at room temperature. From the as-rolled sheet, tensile specimens were mechanically prepared with gauge dimensions of $60 \mathrm{~mm}$ (length) $\times 5 \mathrm{~mm}($ width) $\times 0.5 \mathrm{~mm}$ (thickness). The specimens were solution-treated (ST) at $1173 \mathrm{~K}$ for $1.8 \mathrm{ks}$ under high vacuum atmosphere and subsequently water-quenched. Uniaxial tensile tests were conducted at room temperature using an Instron 5982 machine. Electron backscatter diffraction (EBSD) maps were scanned using a field emission gun scanning electron microscope operating at $20 \mathrm{kV}$. In-situ tensile tests were performed using a Proxima 100-Micromecha machine. Deformation was followed by secondary electron (SE) imaging during the loading state and EBSD scans are recorded at different strains until fracture. Specimens deformed to different levels were then observed by transmission electron microscopy (TEM). The TEM investigations were performed by using a JEOL 2100 microscope operating at $200 \mathrm{kV}$. Specimens for TEM observations were prepared by a conventional twin-jet polishing technique, using a solution of $4 \%$ perchloric acid in methanol, held at about $250 \mathrm{~K}$.

\section{Results and discussion}

The true strain-true stress curve and the corresponding evolution of the work hardening rate $(\theta=\mathrm{d} \sigma / \mathrm{d} \varepsilon)$ of Ti-18Zr-13Mo alloy are shown in Figure 1, as well as the true strain-true stress curve of Ti-12Mo alloy as reference. The present Ti-18Zr-13Mo alloy exhibits comparable mechanical properties as of Ti-12Mo alloy, similarly a high work-hardening rate, reaching about levels of true stress and true strain at necking of $1115 \mathrm{MPa}$ and 0.18 , respectively. It can be noticed that the yield strength (YS) of the alloy is much higher than those of the TRIP/TWIP Ti alloys, developed earlier [13-18, 20-22]. This improvement in the YS can be attributed to solid solution and grain boundary strengthening (GS $=49 \mu \mathrm{m}$, shown in Fig. 2a) in the designed alloy. Compared with Ti-12Mo alloy, the true stress-strain curve of the present alloy from the elastic to plastic region displays without a plateau arising from the stress-induced phase transformation [22], suggesting that the difference of deformation mechanism between the two alloys. 


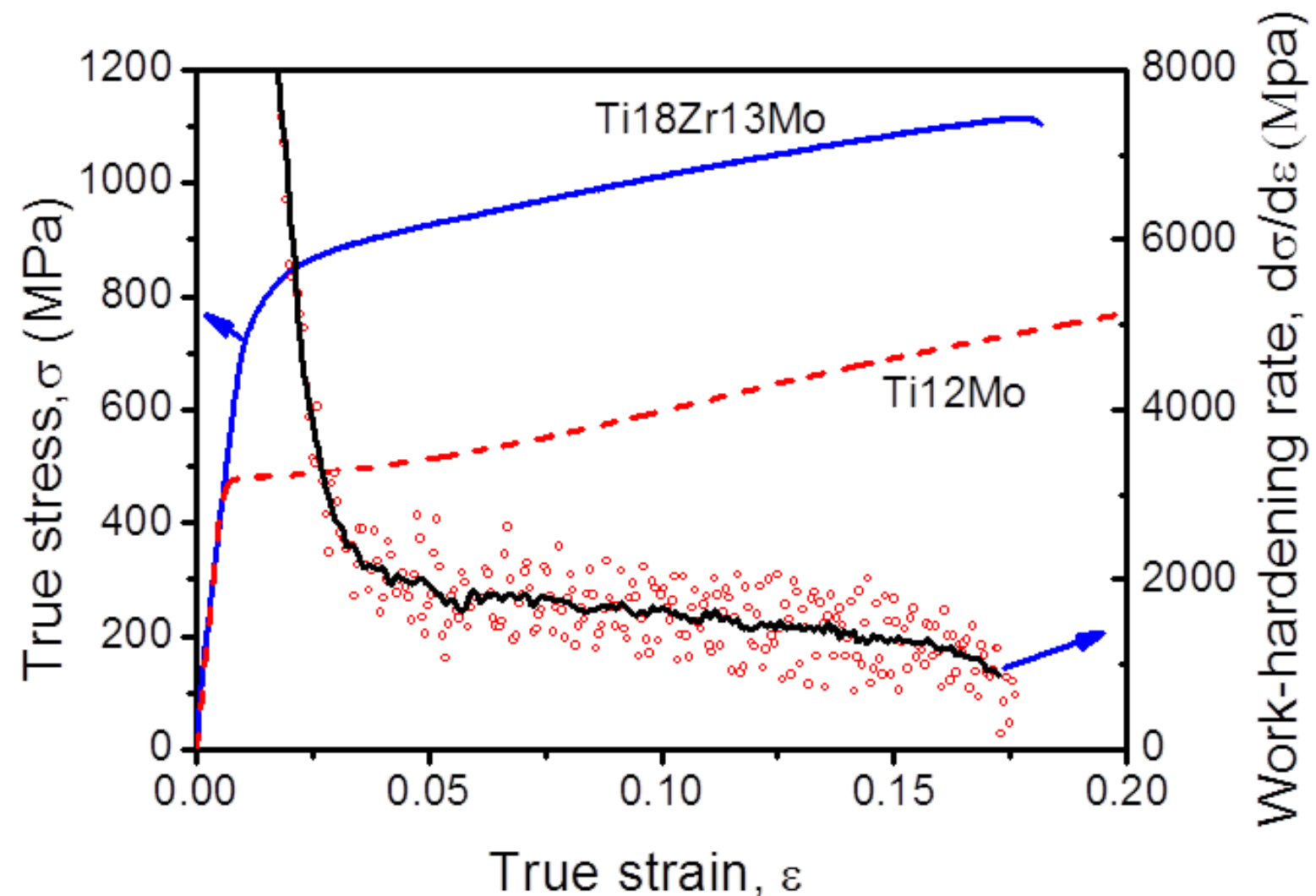

Figure 1. The true strain-true stress curve and the corresponding work hardening rate $(\theta \equiv \mathrm{d} \sigma / \mathrm{d} \varepsilon)$ of Ti-18Zr-13Mo, a TWIP/TRIP Ti-12Mo curve was drawn in dash line for comparison.

Prior to deformation, Figure $2 \mathrm{a}$ shows the as-quenched Ti-18Zr-13Mo alloy consisted of equiaxed single $\beta$ phase grains with an average grain size (GS) of $\sim 50 \mu \mathrm{m}$. It seems that neither annealed twins nor secondary phases have been detected by optical observation. As reported in our very recently paper [24], only $\beta$ phase was detected without evidence of other phases pre- and postdeformation by the X-ray method, suggesting that none of stress-induced phases (e.g stress-induced martensite phase $\alpha^{\prime \prime}$ ) occurred during deformation. The disappearance of stress-induced martensite phases suggests the $\beta$ stability of Ti-18Zr-13Mo alloy higher than that of Ti-12Mo alloy. Furthermore, very minor athermal $\omega\left(\omega_{\mathrm{ath}}\right)$ phase can be detected by the TEM method (shown in Fig. 2b) pre-deformation, meaning $\omega_{\text {ath }}$ nanoparticles precipitated during the quenching process.
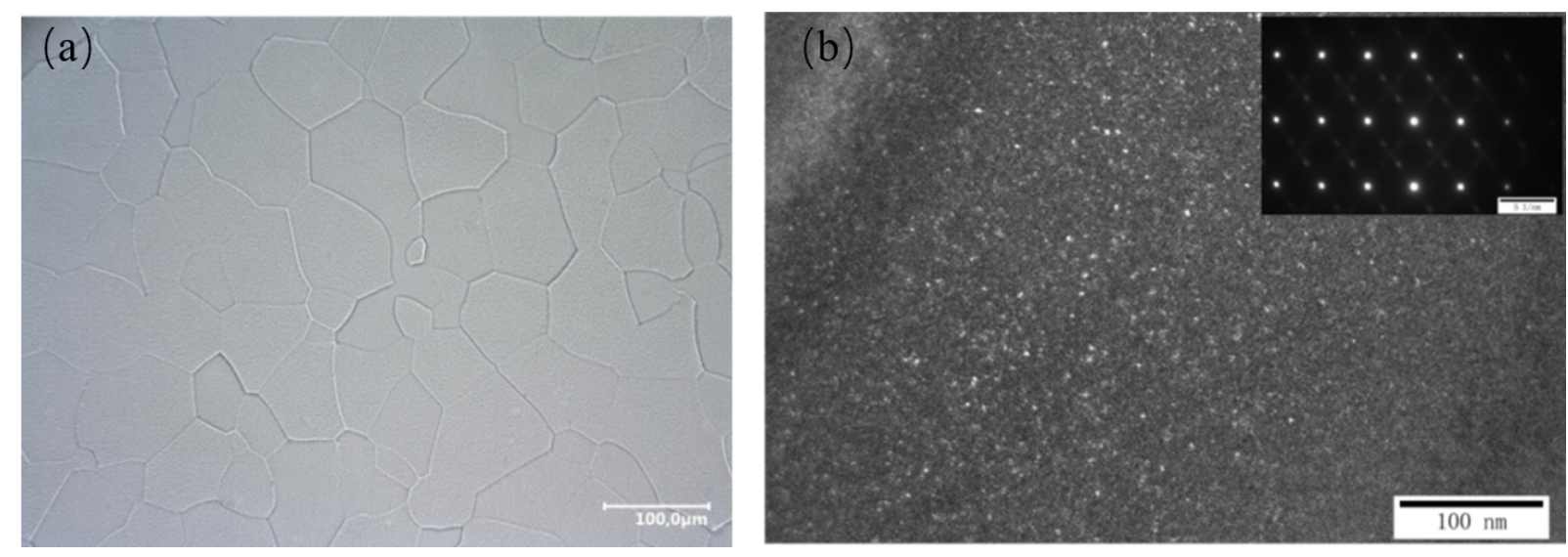

Figure 2 (a) optical observation of as-quenched sample; (b) the dark-field TEM image of as-quenched sample, SAED pattern shown in the inset.

To unveil the evolution of deformation microstructures of the alloy, in-situ SEM/EBSD straining experiments were performed at different strain levels. As reported in our very recently paper [24], the results show that a multimodal twin structure occurred during plastic deformation, such as $\{332\}<113>$ twinning (332T), $\{112\}<111>$ twinning $(112 \mathrm{~T})$ and $\{5811\}<135>$ twinning $(\{5$ 
811 T). Figure 3a-b shows the Image quality (IQ) maps and the corresponding Kernel average misorientation (KAM) maps through EBSD analysis, taken from the same region at strain $\varepsilon=0.03,0.1$ respectively. It can be seen from the IQ images in Fig. 3a$\mathrm{b}$ that the deformation bands, indexed 332T by EBSD IPF maps, progressively multiply and grow with the strain increasing. The KAM maps showed in Fig. 3a-b display that the misorientation distribution from $0^{\circ}$ to $5^{\circ}$ between $\beta$ matrix and twin interfaces. The twin interfaces were of higher degrees on crystalline misorientation, which might probably indicate the serious stress/strain localization to induce the occurrence of twinning. Figure $3 \mathrm{c}$ shows the SEI image at strain $\varepsilon=0.18$ and fracture, respectively. The surface of deformed sample become uneven at the later stage of plastic deformation. A typical SEM fractograph is also shown in Figure $3 c$ (inset). A large amount of fine dimples were observed, which indicate the fracture mode was dominant by the transgranular, dimple type fracture. The ductile fracture results from the interaction between the dislocations and the multimodal twin [24].

(a)

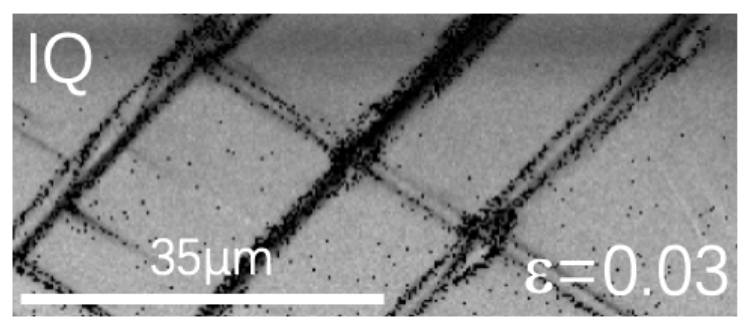

(b)

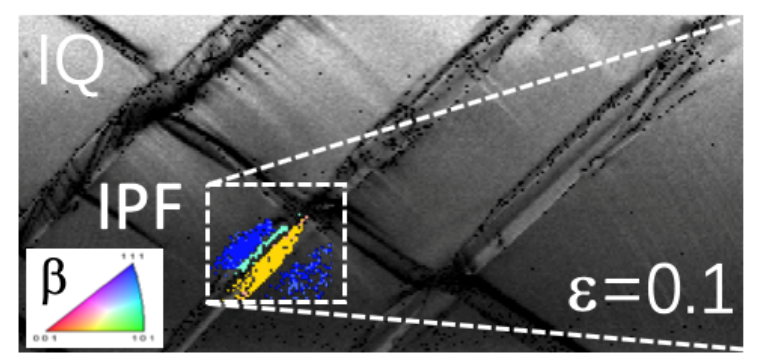

(c)
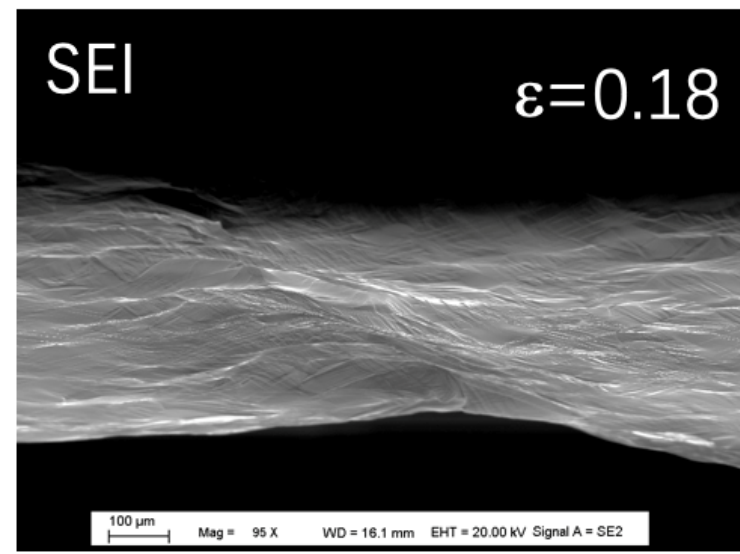
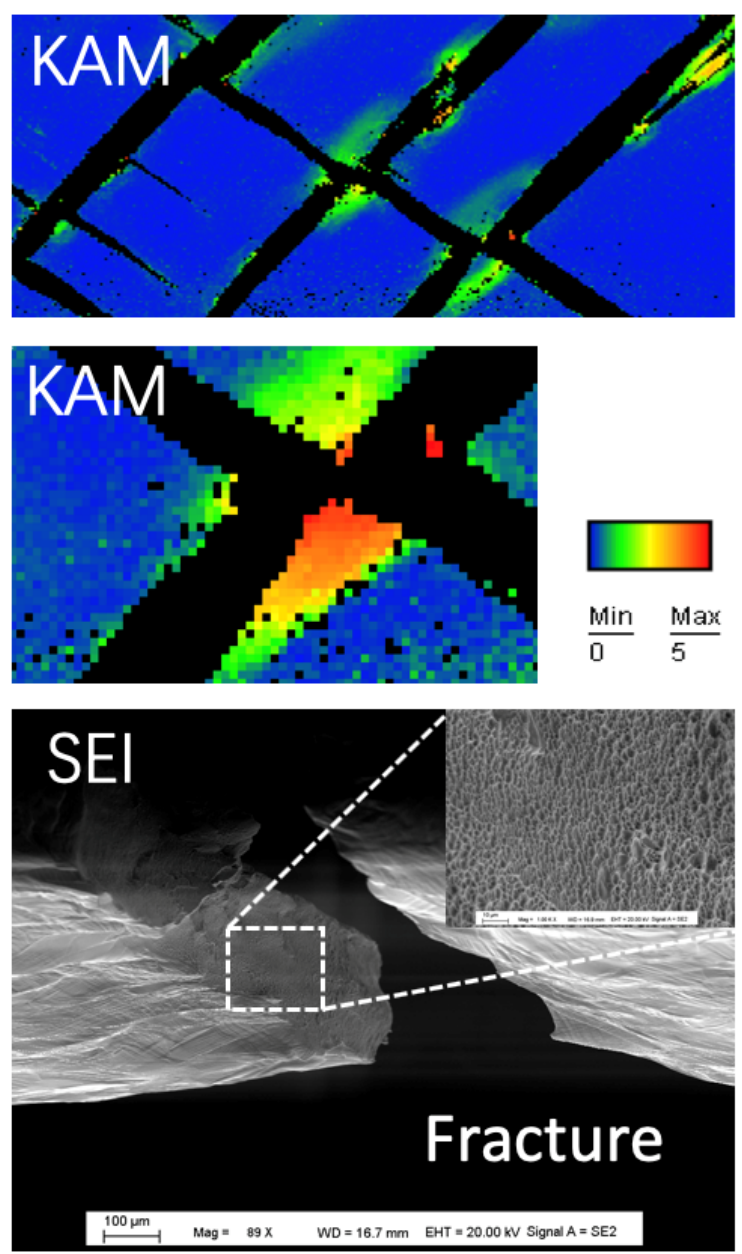

Figure 3. In-situ EBSD images and SEI images during traction: (a-b) IQ, IPF maps and corresponding KAM maps taken from the same grain at $\varepsilon=0.03$ and 0.1 ; (c) SEI images of deformed sample surface at strain $\varepsilon=0.18$ and fracture, the fracture morphology was shown in inset.

The deformation bands were characterized in detailed using TEM analysis. Figure 4 shows TEM micrographs of a deformed sample, illustrating the details of coexistence of dislocation slipping, $\{332\}<113>$ twins and $\{112\}<111>$ twins. Figure 4 (a) and (b) correspond to the bright-field and dark-field images of a set of deformation twin band, respectively. The selected area diffraction pattern at twinning interface (indicated by dashed cycle in Fig. 4(a)) is also shown (inset of Fig. 4a). The twinning system indexed as a typical $\{112\}<111>$ relationship is demonstrated on the diffraction pattern. Fig. 4c shows a large amount of the tangled dislocation slips occurred in the beta matrix. Therefore, it can be seen from Figure 3 and 4 that multiple deformation mechanisms, including $\{332\}<113>$ twinning, nano-scale $\{112\}<111>$ twinning and dislocation slip, occur during tensile deformation in Ti-18Zr-13Mo alloy. The formation of $\{332\}$ twins and nano-scale $\{112\}<111>$ twins during plastic deformation leads to continuous grain subdivision by introducing new sharp interfaces. These interfaces act as barriers to dislocation motion 
and thus reduce the dislocation mean free path, resulting in additional work hardening, a phenomenon referred to as "dynamic Hall-Petch effect" [25].
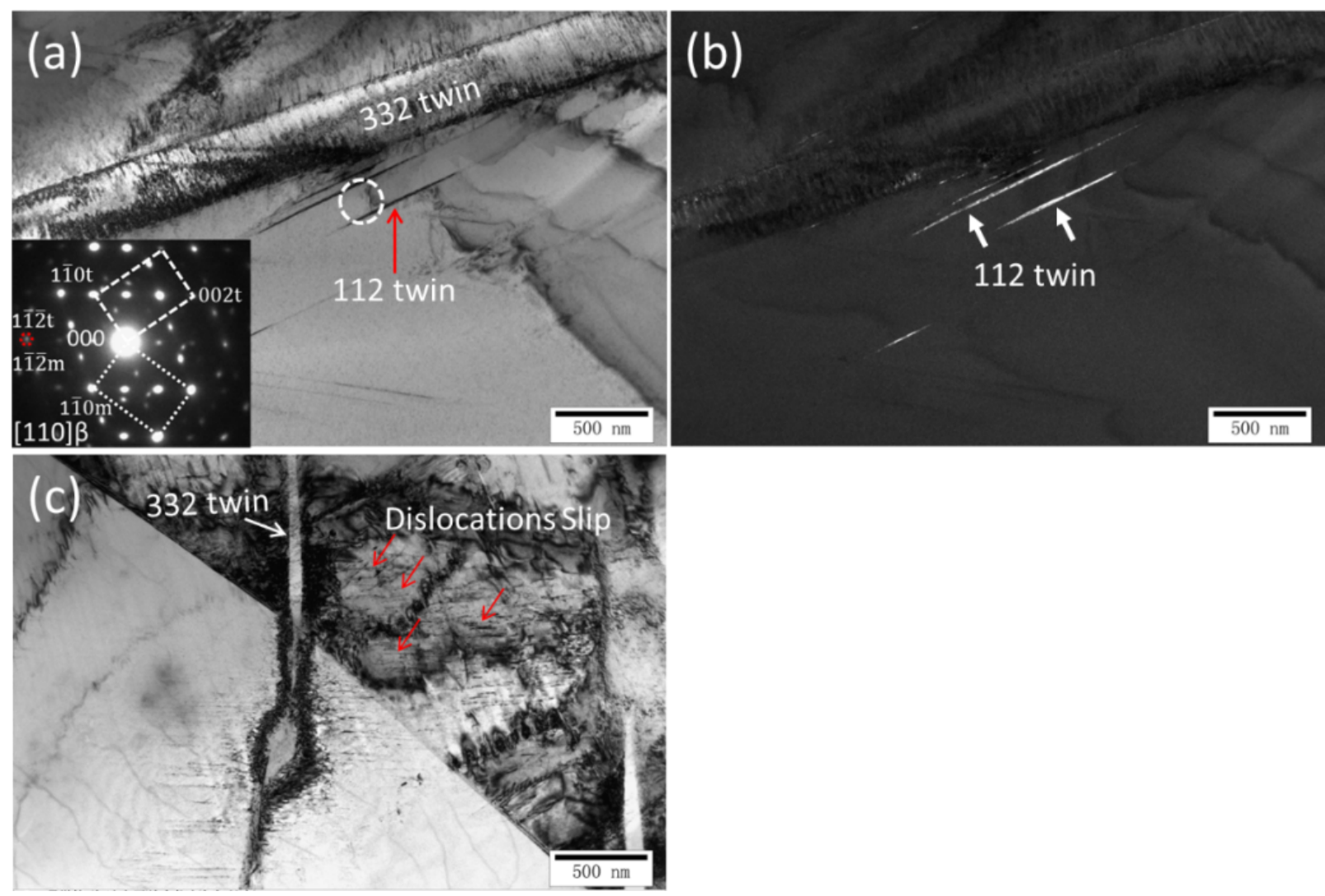

Figure 4. TEM micrographs of deformed sample ( $\varepsilon=0.03$ ): (a) Bright field image of bimodal twinning, SAED pattern shown in the inset; (b) dark field image of nano $\{112\}<111>$ twin bands near a $\{332\}$ twin; (c) bright field image of dislocation slipping occurred in $\beta$ matrix near a $\{332\}$ twin.

\section{Conclusion}

In summary, a new $\beta$-Ti alloy Ti-18Zr-13Mo was designed using the d-electron theory. The alloy exhibits extra high yield, stable strain-hardening rate and enough ductility. According to the investigation of microstructural evolution during plastic deformation, the superior mechanical properties of the alloy benefits from the activation of stress-induced $\{332\}\langle 113\rangle$ and $\{112\}$ $\langle 111\rangle$ twinning and dislocation slip.

\section{Acknowledgments:}

The authors acknowledge Professor Frédéric Prima for the helpful discussions and advices. The work was supported by Fundamental Research Funds for the Central Universities (Grant No. 2018GF13).

\section{References:}

[1] J.C. Williams, E.A. Starke Jr, Acta Materialia 51 (2003) 5775-5799.

[2] O. Ivasishin, P. Markovsky, Y.V. Matviychuk, S. Semiatin, C. Ward, S. Fox, Journal Of Alloys And Compounds 457 (2008) 296-309.

[3] M. Geetha, A.K. Singh, R. Asokamani, A.K. Gogia, Progress in Materials Science 54 (2009) 397-425.

[4] F. Sun, F. Prima, T. Gloriant, Materials Science and Engineering: A 527 (2010) 4262-4269.

[5] S.Q. Zhang, S.J. Li, M.T. Jia, Y.L. Hao, R. Yang, Scripta Materialia 60 (2009) 733-736. 
[6] T.C. Niemeyer, C.R. Grandini, L.M.C. Pinto, A.C.D. Angelo, S.G. Schneider, Journal of Alloys and Compounds 476 (2009) $172-175$.

[7] S. Hanada, O. Izumi, Metallurgical and Materials Transactions A 18 (1987) 265-271.

[8] D. Banerjee, J.C. Williams, Acta Materialia 61 (2013) 844-879.

[9] H.Y. Kim, Y. Ikehara, J.I. Kim, H. Hosoda, S. Miyazaki, Acta Materialia 54 (2006) 2419-2429.

[10] M. Ahmed, D. Wexler, G. Casillas, D.G. Savvakin, E.V. Pereloma, Acta Materialia 104 (2016) 190-200.

[11] J.Y. Zhang, F. Sun, Y.L. Hao, N. Gozdecki, E. Lebrun, P. Vermaut, R. Portier, T. Gloriant, P. Laheurte, F. Prima, Materials Science And Engineering: A 563 (2013) 78-85.

[12] X.H. Min, K. Tsuzaki, S. Emura, K. Tsuchiya, Materials Science and Engineering: A 528 (2011) 4569-4578.

[13] X. Min, X. Chen, S. Emura, K. Tsuchiya, Scripta Materialia 69 (2013) 393-396.

[14] X. Min, S. Emura, F. Meng, G. Mi, K. Tsuchiya, Scripta Materialia 102 (2015) 79-82.

[15] F. Sun, J.Y. Zhang, M. Marteleur, C. Brozek, E.F. Rauch, M. Veron, P. Vermaut, P.J. Jacques, F. Prima, Scripta Materialia 94 (2015) 17-20.

[16] L. Ren, W. Xiao, C. Ma, R. Zheng, L. Zhou, Scripta Materialia 156 (2018) 47-50.

[17] C. Brozek, F. Sun, P. Vermaut, Y. Millet, A. Lenain, D. Embury, P.J. Jacques, F. Prima, Scripta Materialia 114 (2016) 60-64.

[18] V.N. Moiseyev, Titanium alloys: Russian aircraft and aerospace applications, 2005, p. 171-195.

[19] S. Sadeghpour, S.M. Abbasi, M. Morakabati, S. Bruschi, Materials \& Design 121 (2017) 24-35.

[20] S. Sadeghpour, S.M. Abbasi, M. Morakabati, A. Kisko, L.P. Karjalainen, D.A. Porter, Scripta Materialia 145 (2018) $104-108$.

[21] J. Gao, Y. Huang, D. Guan, A.J. Knowles, L. Ma, D. Dye, W.M. Rainforth, Acta Materialia 152 (2018) 301-314.

[22] F. Sun, J.Y. Zhang, M. Marteleur, T. Gloriant, P. Vermaut, D. Laillé, P. Castany, C. Curfs, P.J. Jacques, F. Prima, Acta Materialia 61 (2013) 6406-6417.

[23] M.J. Lai, C.C. Tasan, D. Raabe, Acta Materialia 100 (2015) 290-300.

[24] J. Zhang, F. Sun, Z. Chen, Y. Yang, B. Shen, J. Li, F. Prima, Materials Research Letters 7 (2019) 251-257.

[25] I. Gutierrez-Urrutia, D. Raabe, Acta Materialia 59 (2011) 6449-6462. 